Methods This was cross-sectional in design, conducted in Ido Local Government Area, Oyo State, Nigeria. Using two-stage sampling technique, 595 females were recruited from senior classes in private and government-owned secondary schools. Interviewer-administered questionnaire was used to obtain information on socio-demographic characteristics and history of experiencing DV in the three month period preceding the study. Three domains of DV (physical assault, sexual coercion and injury) were assessed using a modified Conflict Tactics Scales 2. Descriptive statistics and Chi-square test (level of significance $=5 \%$ ) were conducted.

Results Mean age of respondents was $15.7 \pm 1.6$ years. About half $(45.9 \%)$ had ever dated and $45.2 \%$ were currently dating. Among those who had dated, 54.9\% experienced at least one incident of DV. Forms of DV experienced were physical assault (46.5\%), sexual coercion $(27.1 \%)$ and injury (8.8\%). Younger ( $<15$ years) $(71.1 \%)$ compared to older ( $\geq 15$ years) $(52.3 \%)$ adolescents were more likely to be victims of DV. Nearly equal proportions of respondents from polygamous $(55.8 \%)$ and monogamous (54.5\%) homes experienced DV. More adolescents in private (14.4\%) compared to government-owned $(5.7 \%)$ schools suffered DV. There was no significant difference in the prevalence of DV between females currently in a dating relationship (55.3\%) and those not currently dating (53.3\%).

Conclusions The important role age, family type, school type and dating status played in DV victimisation poses the need for programmers to pay robust attention to FA in these categories when designing programs to address this problem.

\section{SITUATION ANALYSIS ON CHILD MALTREATMENT PREVENTION IN ALBANIA}

${ }^{1}$ Gentiana Qirjako, ${ }^{2}$ Dimitrinka Jordanova Pesevska, ${ }^{3}$ Ledia Lazëri, ${ }^{4}$ Dinesh Sethi. ${ }^{1}$ University of Medicine, Faculty of Public Health, Albania; ${ }^{2}$ WHO Consultant on Violence Prevention; ${ }^{3}$ WHO Country Office, Albania; ${ }^{4}$ WHO Regional Office for Europe

10.1136/injuryprev-2016-042156.257

Background Child maltreatment is a leading cause of health inequality and social injustice, with poorer and disadvantages populations being more in risk. The consequences of child abuse and exposure to different adverse childhood experiences in childhood both immediate and long-term consequences, have serious impact on physical, emotional well-being, development and health status of children.

Method During October 2015, a situation analysis on child maltreatment prevention in Albania was carried out, based on information gathered from relevant stakeholders in the country as well as on desk review of existing policy documents and reports. The aim of this analysis was to define the current situation of child maltreatment in Albania and take further actions for preventing in line with the recommendations of the European report on preventing child maltreatment and the WHO European child maltreatment prevention action plan 2015-2020.

Results Over the last decade, Albania has improved policy and legal framework for the protection of children's rights. On the other hand, the child maltreatment prevention and protection have been provided by the several relevant sectors: social, health, educational, police, justice and others. Non-governmental organisations take a part in providing services for children. Existing services are mainly focused on detection and protection of the victims, so further efforts should be done in development of the preventive programmes and evidence based practices tailored for the country context.
Conclusions Current policy and legal framework of the country enables suitable platform for child maltreatment prevention, but still there is a need for stronger policy and legal reinforcement and monitoring. A comprehensive action plan for the prevention of child maltreatment should be developed to significantly contribute in reducing the burden of child maltreatment and risk factors targeting prevention in Albania.

\section{Brain Injuries}

\section{Parallel Tue 1.5}

\section{HEAD INJURIES IN YOUNG CHILDREN; THE FORGOTTEN PANDEMIC}

AB Van As, D Schulman, P Mtambeka, C Mavengere, A Numanoglu. Red Cross War Memorial Children's Hospital, University of Cape Town

\subsection{6/injuryprev-2016-042156.258}

Background Head injuries represent the most common and most serious injury occurring in childhood. We analysed the profile of childhood head injury patients treated in a Paediatric Trauma Unit over a 25 years period.

Methods A retrospective record-based study was performed at the Trauma Unit of the Red Cross War Memorial Children's Hospital in Cape Town, South Africa. The Childsafe South Africa Childhood Injury Surveillance System was data-mined for the information. Inclusion criteria were children under the age of 13 years and presenting with a head injury during the period between January 1991 and July 2025.

Results 10205 children presented after a sustaining a head injury. There were 6457 boys and 3745 girls. In 281 (2.75\%) of cases the children were injured as a result of physical violence. The majority of children presented with superficial lacerations and abrasions, mostly affecting the scalp and skull. Injuries were mainly caused by falls from a variety of heights or were trafficrelated. Almost two-thirds of traffic-related injuries involved children as victims of a motor vehicle crash. The majority of head injuries in young children occurred in the vicinity or within the child's own home. In 56 cases the severity of the injury was not recorded. From the remaining 10146, 6864 (67.3\%) were classified as minor; $2918(28.6 \%)$ as moderate; $225(2.2 \%)$ as severe and $135(1.3 \%)$ children died within 24 hours after admission.

Conclusions Head injuries are a significant and ongoing cause of morbidity in particular of young children and represent the most important component of childhood injuries. Protection of young children, especially in their own home and on the streets requires urgent attention.

\section{RANDOMISED CONTROLLED TRIAL OF A TEXT MESSAGE ALCOHOL INTERVENTION FOLLOWING AN INJURY ADMISSION}

${ }^{1}$ Sarah Sharpe, ${ }^{1}$ Bridget Kool, ${ }^{1}$ Robyn Whittaker, ${ }^{1}$ Arier Lee, ${ }^{1}$ Papaarangi Reid, ${ }^{2}$ lan Civil, ${ }^{3}$ Gordon S Smith, ${ }^{4}$ Matthew Walker, ${ }^{5}$ Vanessa Thornton, 'Shanthi Ameratunga. ${ }^{1}$ University of Auckland, New Zealand; ${ }^{2}$ Auckland City Hospital, New Zealand; ${ }^{3}$ University of Maryland, USA; ${ }^{4}$ North Shore Hospital, New Zealand; ${ }^{5}$ Middlemore Hospital, New Zealand

\subsection{6/injuryprev-2016-042156.259}

Background Despite known benefits, brief interventions (BIs) for problem drinking are often not implemented in trauma care 